\title{
Cardiovascular Clinical Implications of Heart Rate Variability
}

\author{
Mahmoud Hassan Abdelnabi \\ Department of Clinical and Experimental Internal Medicine, Cardiology and Angiology Unit, Medical Research Institute, Alexandria University, Alexandria, Egypt \\ ORCID: \\ Mahmoud Hassan Abdelnabi: https://orcid.org/0000-0001-8016-9049
}

\section{Abstract}

Heart rate variability (HRV) is one of the promising emerging noninvasive modalities that are extensively used nowadays in research and risk stratification of several diseases. Reduced HRV has been linked to several cardiovascular risk factors such as hypertension (HTN) and diabetes mellitus (DM) also; it has been linked and used for years now in the risk stratification of congestive heart failure, coronary artery disease (CAD), and acute myocardial infarction (AMI). Controversial data are present about the effect of coronary artery bypass graft (CABG) on HRV and the use of HRV for risk stratification in post-CABG patients while percutaneous coronary intervention was linked to a dramatic improvement in HRV and improved survival of CAD patients. Although experimental data are present correlating reduced HRV with increased risk for cardiovascular morbidity and mortality, extensive research is required for further implementation in daily clinical use. In this review, we will discuss the current cardiovascular clinical implications and highlight the limitations of usage and future perspective of HRV.

Keywords: Acute myocardial infarction, autonomic nervous system, coronary artery disease, diabetes mellitus, heart rate variability, hypertension, percutaneous coronary intervention, risk stratification

\section{INTRODUCTION}

Heart rate variability (HRV) is the spontaneous fluctuations in the normal sinus rhythm; it can be measured as the standard or the average deviation from the mean R-R intervals of all cardiac cycle length (R-R intervals for normal sinus beats) over a given period..$^{[1,2]}$

HRV is considered a reflection of natural sympathovagal balance on the heart or the normal activity of the autonomic nervous system (ANS).

Several methods have been proposed by the Task Force of the European Society of Cardiology (ESC) and the North American Society of Pacing and Electrophysiology (NASPE) to define and to establish the standards of measurement, physiological interpretation, and clinical use of HRV. ${ }^{[3]}$ Time domain indices, nonlinear geometric measures, and frequency domain indices are considered the standard clinically used parameters. ${ }^{[4]}$ The analysis of HRV data should meet the defined standards of measurement by the Task Force of ESC and NASPE either through the short-term recordings of

Submission: 16-Aug-18 Revision: 03-Oct-18 Accepted: 04-Oct-18

\begin{tabular}{|l|l|}
\hline \multicolumn{2}{|c|}{ Access this article online } \\
\hline Quick Response Code: & Website: \\
& \\
&
\end{tabular}

5 min made under physiologically stable conditions and/or long 24-h recordings (Holters). ${ }^{[3]}$ Over the past years, HRV has been correlated with most cardiovascular diseases and risk factors. ${ }^{[2]}$

\section{Clinical perspective:}

To review the current clinical trials that linked heart rate variability to different cardiovascular risk factors and diseases and to determine usage limitations and future prospectives of heart rate variability as a noninvasive diagnostic modality in risk stratification of several cardiovascular diseases.

\section{Clinical Implications of Heart Rate Variability Hypertension}

One of the most important risk factors for coronary artery disease (CAD) is hypertension (HTN). Numerous studies

Address for correspondence: Dr. Mahmoud Hassan Abdelnabi, Department of Clinical and Experimental Internal Medicine, Cardiology and Angiology Unit, Medical Research Institute, Alexandria University, 165 El-Horeya Rd, Al Ibrahimeyah Qebli WA Al Hadrah Bahri, Qesm Bab Sharqi, Alexandria, Egypt. E-mail: mahmoud.hassan.abdelnabi@outlook.com

This is an open access journal, and articles are distributed under the terms of the Creative Commons Attribution-NonCommercial-ShareAlike 4.0 License, which allows others to remix, tweak, and build upon the work non-commercially, as long as appropriate credit is given and the new creations are licensed under the identical terms.

For reprints contact: reprints@medknow.com

How to cite this article: Abdelnabi MH. Cardiovascular clinical implications of heart rate variability. Int J Cardiovasc Acad 2019;5:37-41. 
have documented the association between cardiac autonomic dysfunction and HTN. ${ }^{[5]}$

Huikuri et al. studied the correlation between HRV and long-standing systemic HTN comparing patients with long-standing HTN with the age-matched normotensive population. The data showed that long-standing HTN results in reduced overall HRV suggesting that low HRV may contribute to increased cardiac mortality in patients with long-standing HTN. ${ }^{[6]}$

Liao et al. examined the association between 2 min of supine HRV and HTN in a random sample derived from the biracial Atherosclerosis Risk in Communities (ARIC) study with a 3 -year follow-up. The results suggested a positive correlation between decreased HRV and HTN and furthermore suggest that decreased HRV was associated with increased risk for HTN ${ }^{[7]}$

Singh et al. conducted a study aiming to compare the measures of HRV between hypertensive and normotensive subjects and to examine the role of HRV as a predictor of new-onset HTN using data derived from the Framingham Heart Study (FHS). HRV was significantly lower in hypertensive men and women while among normotensive men, lower HRV was associated with greater risk of developing HTN. These findings are consistent with the hypothesis that autonomic dysregulation is present in the early stages of HTN. ${ }^{[8]}$

\section{Diabetes mellitus}

Diabetes mellitus (DM) is another important risk factor for CAD has also been linked to decreased HRV. Autonomic neuropathy is a common complication of DM, and the early subclinical detection of autonomic dysfunction may be important for the risk stratification and subsequent management of diabetics. ${ }^{[5]}$

In the first study to examine the relationship between HRV as an indicator of ANS and DM, Liao et al. computed high-frequency power (HF) as index of vagal tone from 2-min recordings of a sample derived from the ARIC and found that DM was associated with a lower HRV than age, race, and gender-matched nondiabetics also, prediabetics were associated with a reduce HRV suggesting that reduced vagal tone may be involved in the pathogenesis of DM. ${ }^{[9]}$

Singh et al. examined the relationship between HRV and blood glucose levels from data derived from the FHS. HRV indices were significantly reduced in diabetics and those with impaired fasting glucose compared to those with normal fasting glucose levels. ${ }^{[10]}$

\section{Heart failure}

The ANS regulation plays an important role in the progression of congestive heart failure (CHF). ${ }^{[11]}$ It may affect the cardiovascular system in heart failure in several ways including downregulating $\beta$-adrenergic receptors, exerting direct toxic effects on the myocardium, and contributing to myocardial remodeling and life-threatening arrhythmias. In this sense, CHF patients are a high-risk group for death. ${ }^{[4]}$

Ventricular tachycardias often occur in patients with compromised left ventricular ejection fraction (LVEF) and up to $80 \%$ of patients may die suddenly with an average $60 \%$ survival at 4 years..$^{[4]}$

Sympathetic activation and reduced vagal tone are usually reflected by a significant increase in low-frequency power (LF) and decrease in HF component and this sufficiently intact sympathetic activation at less advanced stages of CHF reflected by increased LF contribute to arrhythmogenesis and sudden death. ${ }^{[12]}$

In the advanced stages of heart failure, there is a loss of rhythmicity in the LF and HF components. A particular finding is the highly reduced or even undetectable LF in spite of the high levels of sympathetic activation. This behavior of the LF component suggests that the integrity of the sympathetic innervation becomes defective with the progression of CHF. ${ }^{[12]}$ The highly reduced LF power in the advanced stages of CHF may be secondary to abnormalities in central autonomic regulation and impairment of $\beta$-adrenergic receptor sensitivity. ${ }^{[10,13]}$

Patients in very advanced stages of the disease behave as if they had cardiac denervation and loss of neural modulation of cardiac rate, resembling patients with recently transplanted hearts. ${ }^{[14]}$ HRV may be used in patients with CHF as a marker for the prediction of mortality due to progressive LV dysfunction and to sudden cardiac death. ${ }^{[15-19]}$

\section{Coronary artery disease}

Autonomic dysfunction in the form of enhanced sympathetic tone and reduced vagal tone and has been suggested in CAD in the early reports. ${ }^{[20-22]}$

Wennerblom et al. investigated the correlation between uncomplicated CAD and reduced HRV using frequency domain measures and proved that uncomplicated CAD in patients without previous acute myocardial infarction (AMI) or any other diseases were associated with reduced HF and LF HRV as a marker of reduced vagal tone. ${ }^{[23]}$

Feng et al. studied the alteration of HRV time domain measures depending on the characteristics of coronary lesions in stable angina pectoris patients summarizing that compared with a control group, standard deviation of all R-R intervals measured in milliseconds (SDNN) in one-vessel, SDNN, standard deviation of the averages of R-R intervals in all 5-min segments of the entire recording measured in ms (SDANN) in two-vessel disease and in three-vessel disease were lower and compared with two-vessel disease, SDNN, SDANN lower in three-vessel disease. Compared with right CAD, SDNN and SDANN in the left CAD group were lower, while compared with lesions in left circumflex, SDNN in lesions in the left anterior descending artery is lower. ${ }^{[24]}$

Li et al. correlated HRV measures with angiographic CAD in patients with stable angina, independently from other traditional risk factors, comorbidities, medications, or Framingham risk. In addition proved that in patients with high risk of CAD, HRV was even more predictive. Measures of HRV may provide specific advantages in clinical practice 
to improve the risk reclassification of the angiographic CAD ${ }^{[25]}$

Kotecha et al. highlighted that low HRV particularly LF power in a 5-min analysis of HRV is strongly predictive of angiographic CAD regardless of other comorbidities and is clinically useful as an independent risk predictor in obstructive CAD patients with sinus rhythm. ${ }^{[26]}$

\section{Myocardial infarction}

The significance of HRV and its prognostic valve in AMI survivors has been extensively studied over the years. Wolff et al. were the first to assume that HRV measured on the admission of AMI patients can be a predictor of mortality, HRV was measured in 60 -s electrocardiogram strips. Patients with a decreased HRV tended to be older, more likely to have an anterior infarct, and more likely to have heart failure. The study concluded that decreased HRV can be used as an independent predictor of adverse outcome and may predict long-term risk after AMI. ${ }^{[27]}$

Kleiger et al. described the first study that clearly documents the independent and long-term predictive valve of HRV analysis of survivors of AMI through the multicenter postinfarction program (MPIP). 24-h Holter of AMI survivors was evaluated; HRV was proven to be the strongest predictor of mortality. ${ }^{[28]}$

Lombardi et al. studied the sympathovagal interaction in AMI patients using analysis of spectral components of HRV over 1 year. At 2 weeks after AMI, the LF component was significantly increased, the HF component was significantly reduced compared to age-matched control subjects. While at 6 and 12 months after AMI, a progressive decrease in the LF and increase in the HF components was observed. ${ }^{[29]}$

Cripps et al. conducted a study measuring HRV index in 24-h Holter of AMI survivors aiming to assess this novel measurement of HRV and to relate the prognostic significance of decreased HRV using to other well-recognized prognostic variables such as late potentials, reduced LVEF, in-hospital complication, and KILLIP class. ${ }^{[30]}$ Other studies (including a reanalysis of MPIP) have shown that spectral measures of HRV are reduced in survivors of AMI and that decreased values were associated with an increased risk of all-cause mortality. ${ }^{[31]}$

The autonomic tone and reflexes after myocardial infarction trial was a multicenter observational study performed about 10 years after MPIP. The data confirmed that reduced SDNN was associated with an increased mortality during 21 months of follow-up. Furthermore, the combination of low SDNN and LVEF $<35 \%$ carried a higher risk of mortality. ${ }^{[32]} \mathrm{HRV}$ is decreased early after AMI and begins to recover within a few weeks. It is maximally but not fully recovered by $6-12$ months after AMI. ${ }^{[3,34]}$ The assessment of HRV at both the early stage of MI (2-3 days after AMI $)^{[35]}$ and pre-discharge from the hospital (1-3 weeks after acute MI) offers important prognostic information. HRV measured 12-month after AMI also predicts further mortality. ${ }^{[34]}$

\section{Effect of Revascularization on Heart Rate VARIABILITY}

Heart rate variability and coronary artery bypass graft

Previous studies have shown decreased HRV after coronary artery bypass graft (CABG) even more significantly than in patients with $A M{ }^{[36]}$ with a gradual recovery in a few months following the operation. ${ }^{[37,38]}$ Possible reasons for a decreased $\mathrm{HRV}$ after $\mathrm{CABG}$ is a combination of surgical manipulation on the heart and other anatomic structures around the heart, anesthesiological procedures, duration of cardioplegia also, extracorporeal circulation, etc. ${ }^{[39-41]}$ According to some reports, unlike decreased HRV in patients after AMI, decreased post-operative HRV do not have any significant prognostic valve in CABG patients. ${ }^{[42,43]}$ Contrary to those previous reports, recent studies showed that the $\mathrm{CABG}$ patients with post-operative decreased HRV have a higher mortality rate than patients with normal HRV with furthermore research is required for further assessment of the prognostic impact of HRV in $\mathrm{CABG}$ patients. ${ }^{[44]}$

\section{Heart rate variability and percutaneous coronary intervention}

Patients with CAD and exercise-induced angina pectoris have a state of sympathetic hyperactivity ${ }^{[45]}$ and it seems that the myocardial ischemia is the trigger of this sympathetic hyperactivity; hence, theoretically, revascularization by percutaneous coronary intervention (PCI) can restore the normal autonomic balance. ${ }^{[46]}$

Sedziwy et al. studied HRV time domains before PCI and during a 1-year follow-up using serial 24-h Holter monitoring in all patients (before PCI, 14 days, 3, 6, and 12 months after PCI). A significant increase of HRV parameters was noted with statistically significant increase of HRV parameters occurred during the first 3-month follow-up while the results of the next serial recordings ( 6 and 12 months after PCI) demonstrated no additional changes in HRV values; however, they were still significantly higher than before procedure concluding that successful revascularization using PCI leads to an improvement in the autonomic balance of HRV $\cdot^{[47]}$ Aydinlar et al. investigated the effect of PCI on QT dispersion and HRV time and frequency domain parameters and concluded that HRV parameters such as HF component, the square root of the mean of the sum of the squares of differences between adjacent NN intervals measured in ms (rMSSD) and SDNN were significantly increased while LF, LF/HF were significantly reduced. In addition, QT dispersion was significantly decreased with a negative correlation to LF component and LF/HF ratio. ${ }^{[48]}$ Abrootan et al. studied the changes in HRV parameters after elective PCI in patients with stable angina pectoris. Short-term HRV measurement using time domain parameters was done before PCI and 24-h post-PCI. The data indicated that among different time-domain HRV parameters, only SDNN increased significantly, with a considerable yet statistically insignificant increase in rMSSD after PCI. ${ }^{[46]}$ 


\section{Limitations and future prospectives of heart rate variability} In spite of the large number of the currently published experimental and clinical trials concerned with HRV measurements and several clinical implications. Yet still, the use of HRV is limited to research and not routinely used in daily clinical practice. ${ }^{[49]}$ Several reasons have been proposed to explain this issue: First, the pathophysiological mechanism of HRV confirming the direct relation between mortality and reduced HRV is still not fully understood. Second, the clinical application of HRV assessment is limited by the lack of standard methods due to variations of the parameters according to gender, age, drug interferences, and concomitant diseases. Third, so far, there is no consensus about the most accurate HRV parameter for clinical use. Fourth, the sensitivity, specificity, and positive predictive accuracy of HRV are still limited. Particularly, its positive predictive accuracy is modest, ranging from $14 \%$ to $40 \%$. Yet, it has a higher negative predictive value ranging from $77 \%$ to $98 \%$. Fifth, conflicting data ${ }^{[50]}$ have been noted regarding HRV measured after MI, suggesting that it may be insufficient by itself for proper risk stratification in high-risk patients. A combination of HRV and other risk stratification methods including LVEF, nonsustained ventricular tachycardia, and baroreceptor sensitivity may improve the overall predictive accuracy. ${ }^{[32,51,52]}$ and finally, because HRV measurement depends on R-R interval variations, so the measurement is restricted to sinus rhythm patients and to those with a low number of ectopic beats. Due to this issue, some high-risk patients are excluded from HRV analysis due to frequent ectopy or atrial arrhythmias. Approximately $20-30 \%$ of high-risk post-AMI patients and up to $15-30 \%$ CHF patients are excluded for HRV analysis due to frequent ectopic beats or more commonly atrial fibrillation that is observed in up to $15 \%-30 \%$ of patients with $\mathrm{CHF}^{[4]}$

\section{Conclusion}

$\mathrm{HRV}$ is one of the most promising methods for detection and quantification of autonomic dysfunction. Further research is required to define its effectiveness in clinical usage and to validate its usefulness in risk stratification in cardiovascular risk factors and diseases.

\section{Acknowledgment}

The author would like to thank

Professor Dr Moustafa Nawar and Professor Dr Mohammed Ahmed Sadaka

Professors of Cardiology and Angiology, Faculty of Medicine, Alexandria University, Alexandria, Egypt, and

\section{Dr Moataz Ahmed Zaki}

Cardiology and Angiology Unit, Clinical and Experimental Internal Medicine Department, Medical Research Institute, Alexandria University, Alexandria, Egypt.

\section{Financial support and sponsorship}

Nil.

\section{Conflicts of interest}

There are no conflicts of interest.

\section{References}

1. Stein PK, Bosner MS, Kleiger RE, Conger BM. Heart rate variability: A measure of cardiac autonomic tone. Am Heart J 1994;127:1376-81.

2. Kristal-Boneh E, Raifel M, Froom P, Ribak J. Heart rate variability in health and disease. Scand J Work Environ Health 1995;21:85-95.

3. Camm A, Malik M, Bigger J, Breithardt G, Cerutti S, Cohen R, et al. Heart rate variability: Standards of measurement, physiological interpretation and clinical use. Task Force of the European Society of Cardiology and the North American Society of Pacing and Electrophysiology. Circulation 1996;93:1043-65.

4. Sztajzel J. Heart rate variability: A noninvasive electrocardiographic method to measure the autonomic nervous system. Swiss Med Wkly 2004;134:514-22.

5. Thayer JF, Yamamoto SS, Brosschot JF. The relationship of autonomic imbalance, heart rate variability and cardiovascular disease risk factors. Int J Cardiol 2010;141:122-31.

6. Huikuri HV, Ylitalo A, Pikkujämsä SM, Ikäheimo MJ, Airaksinen KE, Rantala AO, et al. Heart rate variability in systemic hypertension. Am J Cardiol 1996;77:1073-7.

7. Liao D, Cai J, Barnes RW, Tyroler HA, Rautaharju P, Holme I, et al. Association of cardiac autonomic function and the development of hypertension: The ARIC study. Am J Hypertens 1996;9:1147-56.

8. Singh JP, Larson MG, Tsuji H, Evans JC, O’Donnell CJ, Levy D, et al. Reduced heart rate variability and new-onset hypertension: Insights into pathogenesis of hypertension: The Framingham heart study. Hypertension 1998;32:293-7.

9. Liao D, Cai J, Brancati FL, Folsom A, Barnes RW, Tyroler HA, et al. Association of vagal tone with serum insulin, glucose, and diabetes mellitus - The ARIC study. Diabetes Res Clin Pract 1995;30:211-21.

10. Singh JP, Larson MG, O'Donnell CJ, Wilson PF, Tsuji H, Lloyd-Jones DM, et al. Association of hyperglycemia with reduced heart rate variability (The Framingham heart study). Am J Cardiol 2000;86:309-12.

11. Packer M. The neurohormonal hypothesis: A theory to explain the mechanism of disease progression in heart failure. J Am Coll Cardiol 1992;20:248-54.

12. Brunner-La Rocca HP, Esler MD, Jennings GL, Kaye DM. Effect of cardiac sympathetic nervous activity on mode of death in congestive heart failure. Eur Heart J 2001;22:1136-43.

13. van de Borne P, Montano N, Pagani M, Oren R, Somers VK. Absence of low-frequency variability of sympathetic nerve activity in severe heart failure. Circulation 1997;95:1449-54.

14. Mortara A, La Rovere MT, Signorini MG, Pantaleo P, Pinna G, Martinelli $\mathrm{L}$, et al. Can power spectral analysis of heart rate variability identify a high risk subgroup of congestive heart failure patients with excessive sympathetic activation? A pilot study before and after heart transplantation. Br Heart J 1994;71:422-30.

15. Ponikowski P, Anker SD, Chua TP, Szelemej R, Piepoli M, Adamopoulos $\mathrm{S}$, et al. Depressed heart rate variability as an independent predictor of death in chronic congestive heart failure secondary to ischemic or idiopathic dilated cardiomyopathy. Am J Cardiol 1997;79:1645-50.

16. Nolan J, Batin PD, Andrews R, Lindsay SJ, Brooksby P, Mullen M, et al. Prospective study of heart rate variability and mortality in chronic heart failure: Results of the United Kingdom heart failure evaluation and assessment of risk trial (UK-heart). Circulation 1998;98:1510-6.

17. Galinier M, Pathak A, Fourcade J, Androdias C, Curnier D, Varnous S, et al. Depressed low frequency power of heart rate variability as an independent predictor of sudden death in chronic heart failure. Eur Heart J 2000;21:475-82.

18. Bilchick KC, Fetics B, Djoukeng R, Fisher SG, Fletcher RD, Singh SN, et al. Prognostic value of heart rate variability in chronic congestive heart failure (Veterans Affairs' Survival Trial of Antiarrhythmic Therapy in Congestive Heart Failure). Am J Cardiol 2002;90:24-8.

19. Musialik-Łydka A, Sredniawa B, Pasyk S. Heart rate variability in heart 
failure. Kardiol Pol 2003;58:10-6.

20. Tristani FE, Kamper DG, McDermott DJ, Peters BJ, Smith JJ. Alterations of postural and valsalva responses in coronary heart disease. Am J Physiol 1977;233:H694-9.

21. Brown KA, Maloney JD, Smith CH, Haritzler GO, Ilstrup DM. Carotid sinus reflex in patients undergoing coronary angiography: Relationship of degree and location of coronary artery disease to response to carotid sinus massage. Circulation 1980;62:697-703.

22. Airaksinen KE, Ikäheimo MJ, Linnaluoto MK, Niemelä M, Takkunen JT. Impaired vagal heart rate control in coronary artery disease. Br Heart J 1987;58:592-7.

23. Wennerblom B, Lurje L, Tygesen H, Vahisalo R, Hjalmarson A. Patients with uncomplicated coronary artery disease have reduced heart rate variability mainly affecting vagal tone. Heart 2000;83:290-4.

24. Feng J, Wang A, Gao C, Zhang J, Chen Z, Hou L, et al. Altered heart rate variability depend on the characteristics of coronary lesions in stable angina pectoris. Anatol J Cardiol 2015;15:496-501.

25. Li HR, Lu TM, Cheng HM, Lu DY, Chiou CW, Chuang SY, et al. Additive value of heart rate variability in predicting obstructive coronary artery disease beyond Framingham risk. Circ J 2016;80:494-501.

26. Kotecha D, New G, Flather MD, Eccleston D, Pepper J, Krum H, et al. Five-minute heart rate variability can predict obstructive angiographic coronary disease. Heart 2012;98:395-401.

27. Wolf MM, Varigos GA, Hunt D, Sloman JG. Sinus arrhythmia in acute myocardial infarction. Med J Aust 1978;2:52-3.

28. Kleiger RE, Miller JP, Bigger JT Jr., Moss AJ. Decreased heart rate variability and its association with increased mortality after acute myocardial infarction. Am J Cardiol 1987;59:256-62.

29. Lombardi F, Sandrone G, Pernpruner S, Sala R, Garimoldi M, Cerutti S, et al. Heart rate variability as an index of sympathovagal interaction after acute myocardial infarction. Am J Cardiol 1987;60:1239-45.

30. Cripps TR, Malik M, Farrell TG, Camm AJ. Prognostic value of reduced heart rate variability after myocardial infarction: Clinical evaluation of a new analysis method. Br Heart J 1991;65:14-9.

31. Bigger JT Jr., Fleiss JL, Steinman RC, Rolnitzky LM, Kleiger RE, Rottman JN, et al. Frequency domain measures of heart period variability and mortality after myocardial infarction. Circulation 1992;85:164-71.

32. La Rovere MT, Bigger JT Jr., Marcus FI, Mortara A, Schwartz PJ. Baroreflex sensitivity and heart-rate variability in prediction of total cardiac mortality after myocardial infarction. ATRAMI (Autonomic tone and reflexes after myocardial infarction) investigators. Lancet 1998:351:478-84.

33. Lombardi F, Sandrone G, Mortara A, La Rovere MT, Colombo E, Guzzetti S, et al. Circadian variation of spectral indices of heart rate variability after myocardial infarction. Am Heart J 1992;123:1521-9.

34. Bigger JT Jr., Kleiger RE, Fleiss JL, Rolnitzky LM, Steinman RC, Miller JP, et al. Components of heart rate variability measured during healing of acute myocardial infarction. Am J Cardiol 1988;61:208-15.

35. Casolo GC, Stroder P, Signorini C, Calzolari F, Zucchini M, Balli E, et al. Heart rate variability during the acute phase of myocardial infarction. Circulation 1992;85:2073-9.

36. Demirel S, Akkaya V, Oflaz H, Tükek T, Erk O. Heart rate variability after coronary artery bypass graft surgery: A prospective 3-year follow-up study. Ann Noninvasive Electrocardiol 2002;7:247-50.

37. Soares PP, Moreno AM, Cravo SL, Nóbrega AC. Coronary artery bypass surgery and longitudinal evaluation of the autonomic cardiovascular function. Crit Care 2005;9:R124-31.

38. Brown CA, Wolfe LA, Hains S, Ropchan G, Parlow J. Heart rate variability following coronary artery bypass graft surgery as a function of recovery time, posture, and exercise. Can J Physiol Pharmacol 2004;82:457-64.

39. Kalisnik JM, Avbelj V, Trobec R, Ivaskovic D, Vidmar G, Troise G, et al. Effects of beating- versus arrested-heart revascularization on cardiac autonomic regulation and arrhythmias. Heart Surg Forum 2007;10:E279-87.

40. Chello M, Mastroroberto P, De Amicis V, Pantaleo D, Ascione R, Spampinato $\mathrm{N}$, et al. Intermittent warm blood cardioplegia preserves myocardial beta-adrenergic receptor function. Ann Thorac Surg 1997;63:683-8.

41. Niemelä MJ, Airaksinen KE, Tahvanainen KU, Linnaluoto MK, Takkunen JT. Effect of coronary artery bypass grafting on cardiac parasympathetic nervous function. Eur Heart J 1992;13:932-5.

42. Milicevic G, Fort L, Majsec M, Bakula V. Heart rate variability decreased by coronary artery surgery has no prognostic value. Eur J Cardiovasc Prev Rehabil 2004;11:228-32.

43. Stein PK, Domitrovich PP, Kleiger RE; CAST Investigators. Including patients with diabetes mellitus or coronary artery bypass grafting decreases the association between heart rate variability and mortality after myocardial infarction. Am Heart J 2004;147:309-16.

44. Lakusic N, Mahovic D, Sonicki Z, Slivnjak V, Baborski F. Outcome of patients with normal and decreased heart rate variability after coronary artery bypass grafting surgery. Int J Cardiol 2013;166:516-8.

45. Gomes ME, Aengevaeren WR, Lenders JW, Verheugt FW, Smits P, Tack CJ, et al. Improving myocardial perfusion by percutaneous coronary intervention reduces central sympathetic activity in stable angina. Clin Cardiol 2010;33:E16-21.

46. Abrootan S, Yazdankhah S, Payami B, Alasti M. Changes in heart rate variability parameters after elective percutaneous coronary intervention. J Tehran Heart Cent 2015;10:80-4.

47. Sedziwy E, Olszowska M, Tracz W, Pieniazek P. Heart rate variability in patients treated with percutaneous transluminal coronary angioplasty. Przegl Lek 2002;59:695-8.

48. Aydinlar A, Sentürk T, Ozdemïr B, Kaderlï AA, Aydin O. Effect of percutaneous transluminal coronary angioplasty on QT dispersion and heart rate variability parameters. Cardiovasc J Afr 2009;20:240-4.

49. Huikuri HV, Mäkikallio T, Airaksinen KE, Mitrani R, Castellanos A, Myerburg RJ, et al. Measurement of heart rate variability: A clinical tool or a research toy? J Am Coll Cardiol 1999;34:1878-83.

50. Huikuri HV, Tapanainen JM, Lindgren K, Raatikainen P, Mäkikallio TH, Juhani Airaksinen KE, et al. Prediction of sudden cardiac death after myocardial infarction in the beta-blocking era. J Am Coll Cardiol 2003;42:652-8.

51. Farrell TG, Bashir Y, Cripps T, Malik M, Poloniecki J, Bennett ED, et al. Risk stratification for arrhythmic events in postinfarction patients based on heart rate variability, ambulatory electrocardiographic variables and the signal-averaged electrocardiogram. J Am Coll Cardiol 1991;18:687-97.

52. Odemuyiwa O, Farrell TG, Malik M, Bashir Y, Millane T, Cripps T, et al. Influence of age on the relation between heart rate variability, left ventricular ejection fraction, frequency of ventricular extrasystoles, and sudden death after myocardial infarction. Br Heart J 1992;67:387-91. 